\title{
Planetary wave oscillations in sporadic $E$ layer occurrence at Wuhan
}

\author{
Xiaomin Zuo ${ }^{1,2,3,4}$ and Weixing Wan ${ }^{1}$ \\ ${ }^{1}$ Institute of Geology and Geophysics, Chinese Academy of Sciences, Beijing, 100029, China \\ ${ }^{2}$ Mathematics and Physics Department, China University of Geosciences, 430074, China \\ ${ }^{3}$ Wuhan Institute of Physics and Mathematics, Chinese Academy of Sciences, China \\ ${ }^{4}$ Graduate School, Chinese Academy of Sciences, China
}

(Received September 23, 2007; Revised November 26, 2007; Accepted January 7, 2008; Online published July 4, 2008)

\begin{abstract}
Quasi 6-day oscillations in $E_{\mathrm{s}}$ occurrence were observed to occur in relation with planetary wave activity at Wuhan, China $\left(30.6^{\circ} \mathrm{N}, 114.5^{\circ} \mathrm{E}\right)$. Wavelet analysis of $E_{\mathrm{s}}$ occurrence time series revealed that a strong 5- to 7-day oscillation was present during the period from about day 120 to 137 of 2003 . The same quasi 6-day planetary wave oscillation was also found to dominate the spectrum of concurrent wind data measured in the 80- to $100-\mathrm{km}$ region by a meteor radar, in agreement with the $E_{\mathrm{s}}$ occurrence. There is also a great deal of similarity between the 5- to 7-day band-pass filtered waveforms of $E_{\mathrm{s}}$ occurrence and the wind data. By estimating the wave phase changes with altitude, the quasi 6-day PW in the zonal wind was found to be in phase with the sporadic $E$ layer critical frequency, $f_{\mathrm{o}} E_{\mathrm{s}}$, at about $115 \mathrm{~km}$, close to the observed $E_{\mathrm{s}}$ height. The quasi 6-day PW modulation was also present in the amplitude of the 12-h and 24-h periodicities which existed in the $f_{\mathrm{o}} E_{\mathrm{s}}$ time series. The present results provide new evidence in favor of a planetary wave indirect role on $E_{\mathrm{s}}$ formation through the modulation of tides, which in line with previous studies by Haldoupis and Pancheva (2002), and Pancheva et al. (2003).
\end{abstract}

Key words: Sporadic $E$ layers, planetary waves, atmospheric tides, PW modulation of tides.

\section{Introduction}

Midlatitude sporadic $E\left(E_{\mathrm{s}}\right)$ layers, which are thin plasma layers of enhanced metallic ion concentration that form frequently in the midlatitude $E$ region ionosphere, have been a topic of intensive research for quite a long time (see review articles by Whitehead, 1989; Mathews, 1998). The formation of the layers is explained by the wind shear theory (see Whitehead, 1961). On the other hand, several new results in the last decade suggest that the generation of sporadic $E$ is not yet fully understood. A possible link between $E_{\mathrm{s}}$ and atmospheric planetary waves (PWs) has recently attracted considerable attention.

Planetary waves are global scale, quasi-periodic oscillations in temperature, pressure, density and wind of the atmosphere, with typical periods in the range of about 2-20 days. They are mainly of tropospheric origin and can affect the atmospheric dynamics in the lower thermosphere between 80 and $150 \mathrm{~km}$ (see Forbes, 1994). Tsunoda et al. (1998) and Voiculescu et al. (1999) were the first to provide evidence for planetary wave effects on midlatitide backscatter and the sporadic $E$ layer occurrence. Furthermore, Voiculescu et al. (2000) analyzed measurements of midlatitude $E$ region coherent backscatter obtained during four summers with SESCAT (sporadic $E$ SCATter experiment), a 50-MHz Doppler radar system operating in Crete, Greece, concurrent ionosonde recordings from the same ionospheric volume obtained with a CADI (Canadian Advanced Digital Ionosonde) for one of these summers and

Copyright (c) The Society of Geomagnetism and Earth, Planetary and Space Sciences (SGEPSS); The Seismological Society of Japan; The Volcanological Society of Japan; The Geodetic Society of Japan; The Japanese Society for Planetary Sciences; TERRAPUB simultaneous neural wind data from the mesopause region around $95 \mathrm{~km}$, measured in Germany. The results suggested that planetary wave effect on sporadic $E$ is a viable option, which introduces a new element into the physics of midlatitude $E$ region layering phenomena. A possible mechanism for the explanation of the PW effects on $E_{\mathrm{s}}$ was proposed by Shalimov et al. (1999). This was followed by a theoretical model (Shalimov and Haldoupis, 2002) postulating a direct role for the PWs on $E_{\mathrm{s}}$ formation which relied on large-scale accumulation of metallic ions in the midlatitude $E$ region ionosphere driven by $\mathrm{PW}$ horizontal wind shears.

The first direct experimental evidence in favor of a PW role on $E_{\mathrm{s}}$ generation was provided by Haldoupis and Pancheva (2002). They analyzed $f_{\mathrm{o}} E_{\mathrm{s}}$ data from a number of ionosonde stations covering a large longitudinal sector to find that a strong 7-day period oscillation in $E_{\mathrm{s}}$ was closely related with a simultaneous 7-day PW present in the mesosphere and lower thermosphere (MLT region) winds, which was detected with meteor radars and from space with satellites. Pancheva et al. (2003) took this work a step further to show that the effects of PW on $E_{\mathrm{s}}$ were indirect through the PW modulation of the diurnal and semidiurnal tides in the MLT region.

The eight ionosonde stations mentioned in the paper of Haldoupis and Pancheva (2002) were all located in the European and North American sectors. It is therefore useful to investigate a similar data set obtained in the Asia sector which is subject to the "Far East Anomaly" (e.g., Smith, 1957). Also, in the work of Pancheva et al. (2003), the analysis was based on concurrent mesospheric neutral winds and ionosonde $f_{\mathrm{o}} E_{\mathrm{s}}$ data from nearby, but different, locations. We have studied the same problem as Pancheva et 
al. (2003) did, we have used a complete data set in which all (ionosonde $f_{\mathrm{o}} E_{\mathrm{s}}$ and MLT wind) measurements were done at the same exactly location, that is, at Wuhan, China $\left(30.6^{\circ} \mathrm{N}, 114.5^{\circ} \mathrm{E}\right)$. We believe this co-location of all instrumentation will certainly be more advantageous for this kind of correlative studies.

The present paper is organized as follows: the planetary wave periodicities in $E_{\mathrm{s}}$ occurrence at Wuhan are presented in Section 2, followed by the analysis of wind measurements in Section 3. Detailed comparisons of the quasi 6day periodicities found in $E_{\mathrm{s}}$ and the wind data are made in Section 4, which is followed by a summary and discussion in Section 5.

\section{Planetary Wave Periodicities in $E_{\mathrm{s}}$ Occurrence at Wuhan}

We first obtained the daily occurrence of $E_{\mathrm{s}}$ layers (for cases when $f_{\mathrm{o}} E_{\mathrm{s}}>5 \mathrm{MHz}$ ) at Wuhan, and then Fourier analyzed the time series for the period from day 120 to 260 of 2002 in order to compute the corresponding spectrum. Note that small data gaps were filled by using a common cubic interpolation method. Figure 1 displays the time sequences of $E_{\mathrm{s}}$ occurrence in the top panel and the corresponding Fourier power spectrum in the bottom panel. It shows a pronounced daily variability in $E_{\mathrm{s}}$ occurrence with periods ranging from two to several days, as evidenced from the normalized Fourier power spectrum in the bottom panel. The spectrum shows two dominant periods at about 7 and 15 days, respectively, which are common prevailing periodicities in the planetary wave band.

To reduce data gaps, which are due to the absence of the layers at times, daily $E_{\mathrm{s}}$ occurrences was selected from day 114 to 151 of 2003 , when $E_{\text {s }}$ occurrence was fairly continuous. Continuous Morlet wavelet analysis was applied to the time series of $E_{\mathrm{s}}$ occurrence. The wavelet method has become a favored tool in geophysics for analyzing non stationary time series. By decomposing the time series into the time-period space, the wavelet analysis transform can determine both the dominant periodicities and their dynamic change (e.g., Torrence and Compo, 1998). As shown in Fig. 2, in the period time spectrogram seen in the bottom panel, a quasi 6-day (5-7 day) oscillation dominates the spectrum for the time interval from about day 120 to 137 .

To investigate if the long-term periodicity owes its presence to geomagnetic activity, the time series of the daily averaged $\mathrm{Kp}$ and Ap index corresponding to the same time intervals were analyzed as well. The quasi 6-day oscillation under consideration did not occur in the $\mathrm{Kp}$ and $\mathrm{Ap}$ spectrograms (not show here). In addition, poor correlation between $E_{\mathrm{s}}$ occurrence and geomagnetic activity was found. The computed correlation coefficients of $E_{\mathrm{s}}$ occurrence with $\mathrm{Kp}$ and Ap were equal to -0.16 and -0.08 , respectively. The lack of correlation between $E_{\mathrm{s}}$ and geomagnetic activity is a well-known fact (see Whitehead, 1989), whereas its absence has also been verified in previous PW$E_{\mathrm{s}}$ studies by Voiculescu et al. (2000) and Haldoupis and Pancheva (2002).
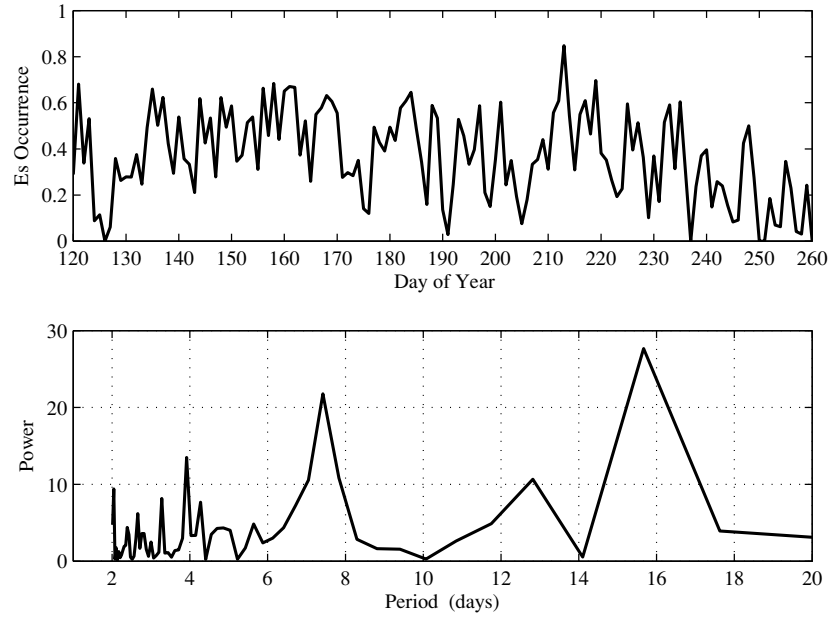

Fig. 1. Time sequence of $E_{\mathrm{s}}$ occurrence and the corresponding Fourier power spectrum for the time interval from day 120 to 260 of 2002 at Wuhan.
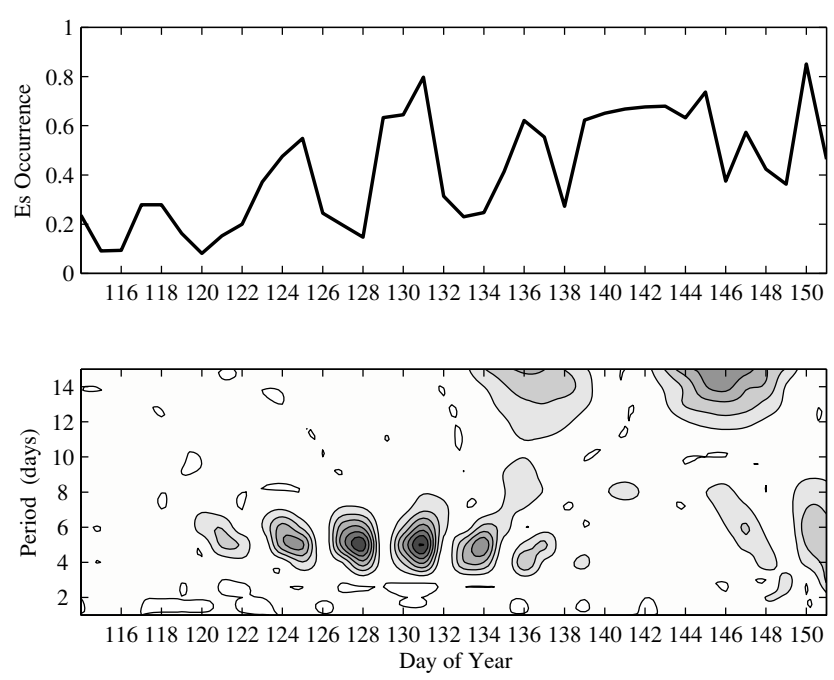

Fig. 2. Time sequence of $E_{\mathrm{s}}$ occurrence and the corresponding wavelet spectrogram for the time interval from day 114 to 151 of 2003 at Wuhan.

\section{Quasi 6-day Period Variations in MLT Winds at Wuhan}

Given this dominant quasi 6-day PW event in $E_{\mathrm{s}}$ occurrence and the need to search for a likely $\mathrm{PW}-E_{\mathrm{s}}$ relationship, the next step was to analyze the concurrent wind observations over Wuhan. The wind data were obtained from an all sky interferometric meteor radar at Wuhan with a peak power of $7.5 \mathrm{~kW}$, a duty cycle of $10 \%$ at a frequency of $38.7 \mathrm{MHz}$ and a range sampling resolution of $2 \mathrm{~km}$ since January 2002, which commenced operation on 29 January 2002. The radar is a commercial VHF system manufactured by Atmospheric Radar Systems of Australia (ATRAD), and it is almost identical to the Buckland Park meteor radar in Australia and the earlier SKiYMET system in Canada (Hocking et al., 2001; Holdsworth et al., 2004). Almost continuous observations have been carried out from February 2002, apart from a 10-day interruption in February 2002 and a larger data gap of 56 days from February 26 to April 22 in 2003 . The parameters used for routine observations 

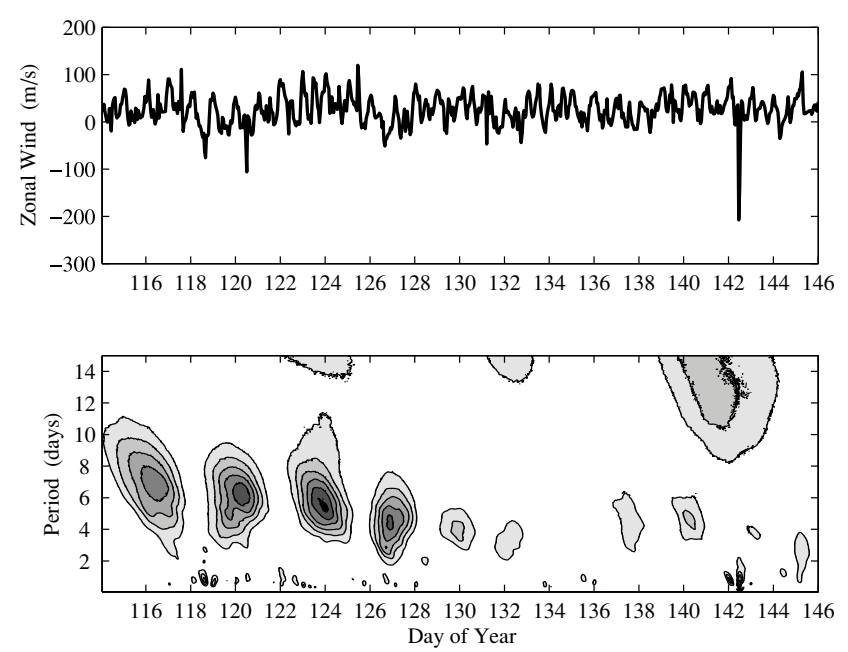

Fig. 3. Time sequence of hourly zonal wind at an altitude of $94 \mathrm{~km}$ and the corresponding wavelet spectrogram for the time interval from day 114 to 145 of 2003 at Wuhan.
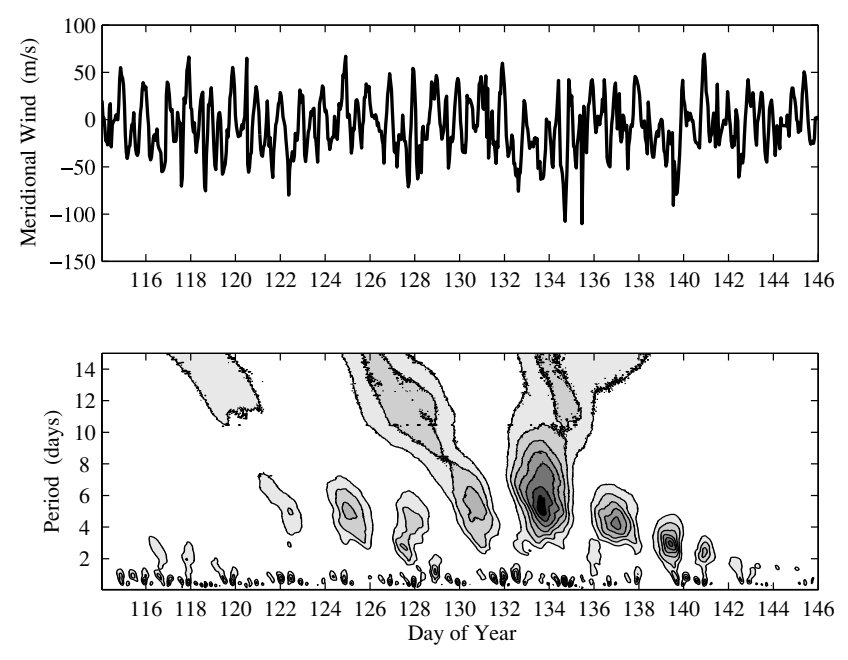

Fig. 4. Same as in Fig. 3 but for the meridional wind.

and the data analysis methodology are described by Xiong et al. (2004).

Although the quasi 6-day planetary wave oscillation is present in the wind data in the entire 80 - to $100-\mathrm{km}$ altitude range, here we select and show the observations at $94 \mathrm{~km}$. Continuous time series wavelet analysis was performed on hourly mean wind speeds during the period from day 114 to 145 of year 2003. The analysis results of zonal and meridional wind are shown in Figs. 3 and 4, respectively, displaying in the upper panel the time series and in the lower panels the period versus time spectrograms. As seen, a dominant quasi 6-day period oscillation occurred on day 115 and persisted about 15 days in the zonal wind. Note that this appeared somewhat ahead of the oscillation present in $E_{\mathrm{s}}$ occurrence. A 6-day periodicity was also present in the meridional wind from day 124 to 138 , being coincident with the quasi 6-day oscillation in the $E_{\mathrm{s}}$ occurrence. It is interesting to note that concomitant to the 6-day event, around day 139, a 3-day periodicity in the meridional wind was also present.

\section{Comparison of Quasi 6-day Waves in $E_{\mathrm{s}}$ and Wind Data}

In order to investigate the amplitude of the oscillations in both the $E_{\mathrm{s}}$ occurrence and the winds in more detail, a fiveorder Butterworth band-pass filter-as applied by Xiong et al. (2006) — was used which was centered on 6 days with a full width of 3 days. The band-pass filter analysis was performed on the time series of daily $E_{\mathrm{s}}$ occurrence and daily mean wind speeds covering the altitude range from 84 to $100 \mathrm{~km}$, with a $4-\mathrm{km}$ interval, for the period from day 100 to 200 of 2003.

As shown in Fig. 5, the $E_{\mathrm{s}}$ occurrence manifests a strong quasi 6-day periodicity from day 115 to 135 , with the strongest peak located around day 125 , while the gap seen in the figure is due to data losses. For comparison with the $E_{\mathrm{s}}$ occurrence, the band pass filtered waveforms of the zonal and the meridional component are shown in Figs. 6 and 7 , respectively. The different altitudes are denoted as follows: $h=84 \mathrm{~km}$, with thick solid line; $h=88 \mathrm{~km}$, the thick dotted line; $h=92 \mathrm{~km}$, the thick dash-dotted line; $h=96 \mathrm{~km}$, the thin solid line; $h=100 \mathrm{~km}$, with thin solid line and dots. As seen, the maximum amplitude of the zonal wind oscillation occurred at the altitude of $92 \mathrm{~km}$, reaching about $18 \mathrm{~m} / \mathrm{s}$ and lasting for two to three cycles from day 120 to 140 . The waveforms at other altitudes displayed their largest amplitudes during the period from day 120 to 140 as well, but these were weaker than those seen at $92 \mathrm{~km}$. Regarding the oscillation in the meridional wind, the largest amplitude occurred between day 120 and about day 140, with values nearing $13 \mathrm{~m} / \mathrm{s}$. The present results show that the quasi 6-day band-pass-filtered $E_{\mathrm{s}}$ occurrence has the same character with that of the neutral wind, which means that a common oscillation with a period inside the PW band is present simultaneously in both the winds and the sporadic $E$ layer occurrence. This is in agreement with the AugustSeptember 1993 event studied by Haldoupis and Pancheva (2002).

Further, the time series of mean hourly wind speeds for the period from day 120 to 140 of year 2003, when the quasi 6-day PW activity was strongest, were analyzed by applying a least-square fitting algorithm (see Hocking et al., 2001 for more details) to estimate the phase changes of the quasi 6-day PW for all altitudes from 84 to $100 \mathrm{~km}$ (every $2 \mathrm{~km}$ ). Figure 8 summarizes the phase variation with altitude of the quasi 6-day PW in the zonal (left panel) and meridional wind (right panel), showing a phase decrease with increasing altitude in both components because of the downward phase propagation of the PW. The wave phase propagated vertically downward with a mean altitude rate of about $2-3 \mathrm{~h} / \mathrm{km}$.

Further, we also worked out the phase of the quasi 6-day periodicity in $f_{\mathrm{o}} E_{\mathrm{s}}$ by analyzing the time series of hourly means for the same internal. Assuming that the quasi 6day wave in zonal wind maintains about $2-3 \mathrm{~h} / \mathrm{km}$ rate of phase change with altitude for heights above $100 \mathrm{~km}$, we found that the $\mathrm{PW}$ in the zonal wind and $E_{\mathrm{s}}$ periodicities to be in phase at about $115 \mathrm{~km}$. Note that no consideration was taken for the meridional component since the vertical plasma motion in the formation process is believed to be controlled mostly by the zonal wind shears below about 


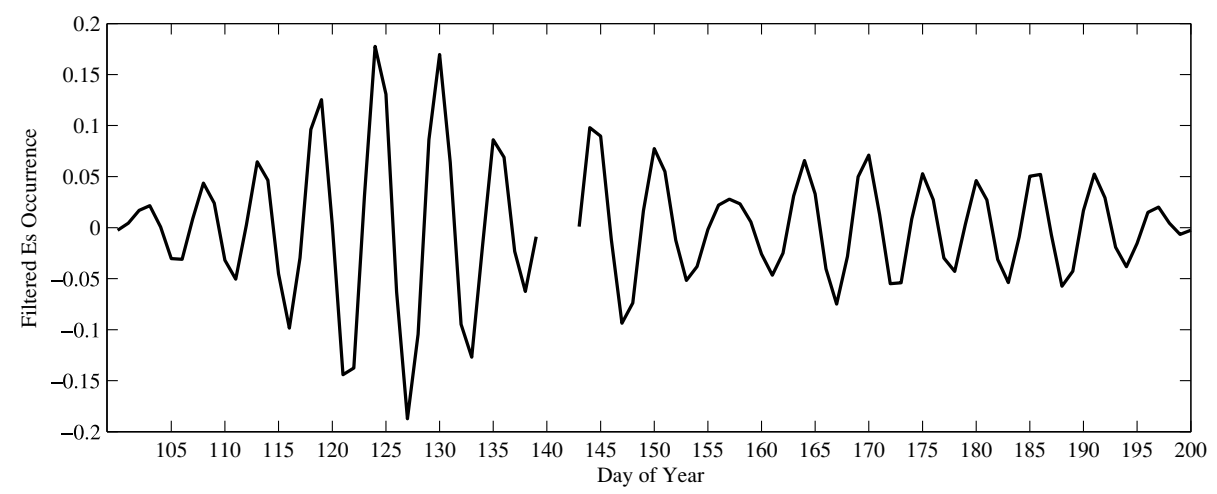

Fig. 5. The quasi 6-day band-pass-filtered daily $E_{\mathrm{s}}$ occurrence time series for the period from day 100 to 200 of 2003 at Wuhan.

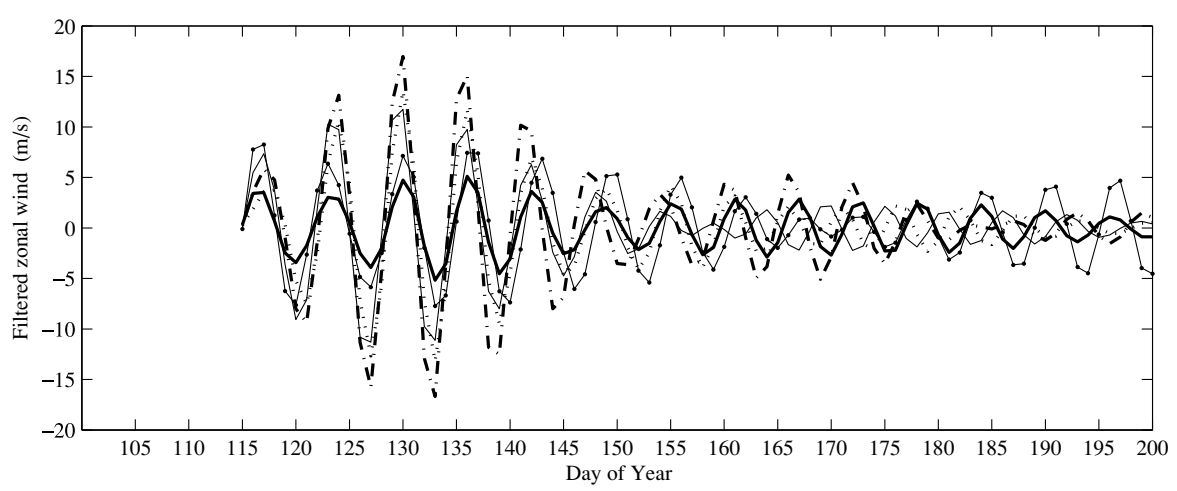

Fig. 6. The quasi 6-day band-pass-filtered daily mean zonal wind measured at five different altitude levels between 84 and $100 \mathrm{~km}$ for the period from day 114 to 200 of 2003 at Wuhan with a data gap from day 100 to 113 . The different altitudes are denoted as follows: thick solid line, $h=84 \mathrm{~km}$; thick dotted line, $h=88 \mathrm{~km}$; thick dash-dotted line, $h=92 \mathrm{~km}$; thin solid line, $h=96 \mathrm{~km}$; thin solid line and dots, $h=100 \mathrm{~km}$.

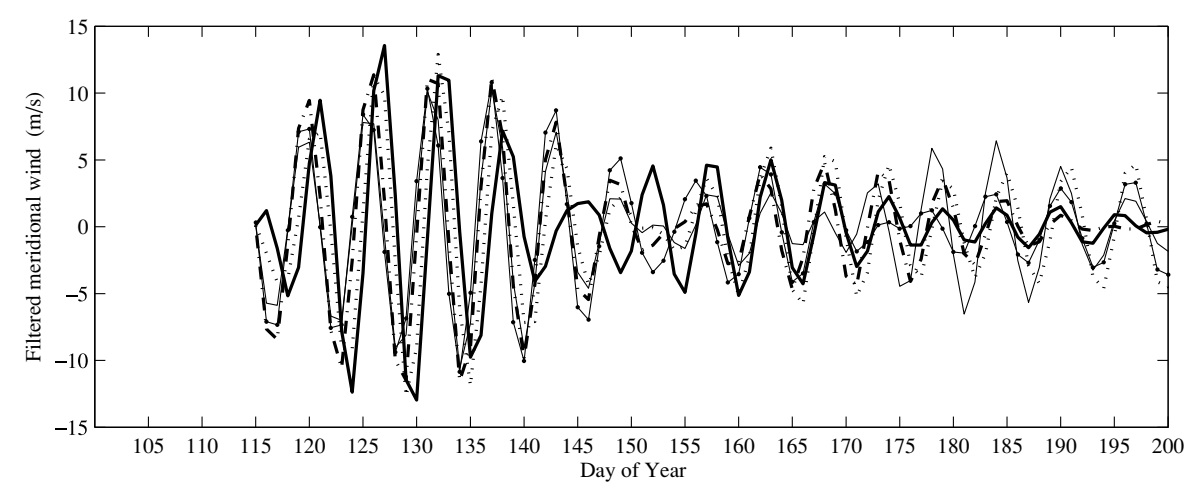

Fig. 7. Same as in Fig. 6 but for the meridional wind.

$120 \mathrm{~km}$ (Pancheva et al., 2003; Haldoupis et al., 2004). Since the mean height of $E_{\mathrm{s}}$ for the period from day 120 to 140 of the year 2003 is estimated from the ionosonde data to be at about $111 \mathrm{~km}$, the phase agreement mentioned above is fairly good. Although the agreement does not necessarily imply a direct effect of PW on $E_{\mathrm{s}}$ because the estimated results were rough and based on given premise, a direct PW role cannot apparently be excluded and might be at work just as the new mechanism proposed by Shalimov et al. (1999), which have been outlined in Section 1. However, in the present paper we hypothesized that PWs play an indirect role and then tested this hypothesis by using the methodology of Pancheva et al. (2003).

Given that atmospheric tidal winds play a fundamental role on $E_{\mathrm{s}}$ formation, it was postulated that a PW affects $E_{\mathrm{s}}$ by modulating the tidal wind amplitudes, apparently at lower altitudes. We have been directed to this postulation by the work of Pancheva et al. (2003) who used a detailed time series demodulation methodology to show that $E_{\mathrm{s}}$ is affected by the PWs indirectly through the PW-modulation of the tidal wind amplitudes. To test this in the present study, wavelet transform analysis was performed on the time series of the $f_{\mathrm{o}} E_{\mathrm{s}} 12$ - and 24-h periodicity amplitudes for the interval from day 120 to 140 of 2003 . The amplitudes were obtained from the $f_{\mathrm{o}} E_{\mathrm{s}}$ time series by using the least-square fitting algorithm of Hocking et al. (2001). The results are presented in Fig. 9 which shows the wavelet spectrograms of the 12- and 24-h periodicity amplitudes. As seen, strong 

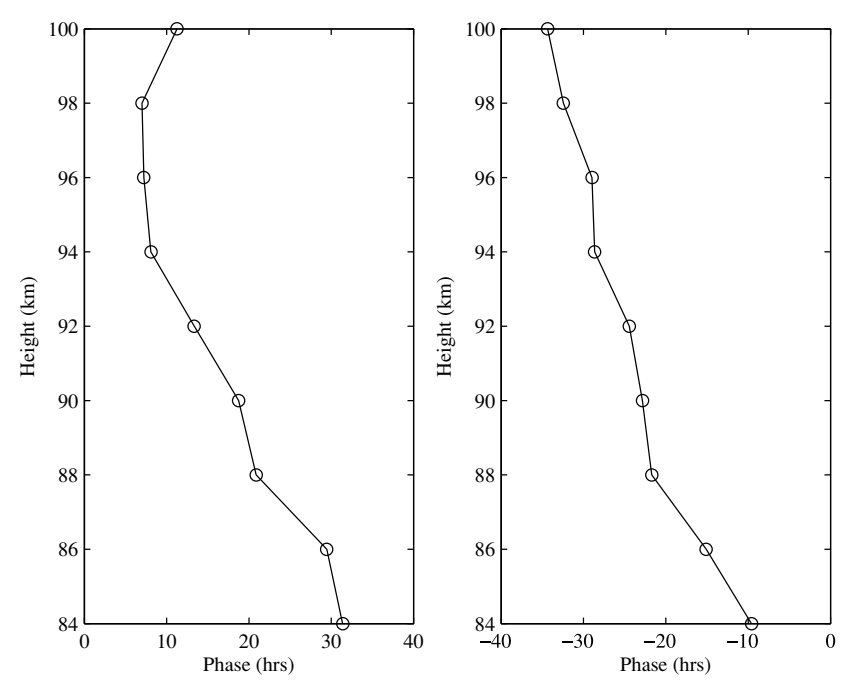

Fig. 8. The quasi 6-day wave phases for all altitudes of the zonal wind (left) and the meridional wind (right) for the period from day 120 to 140 of year 2003 at Wuhan.
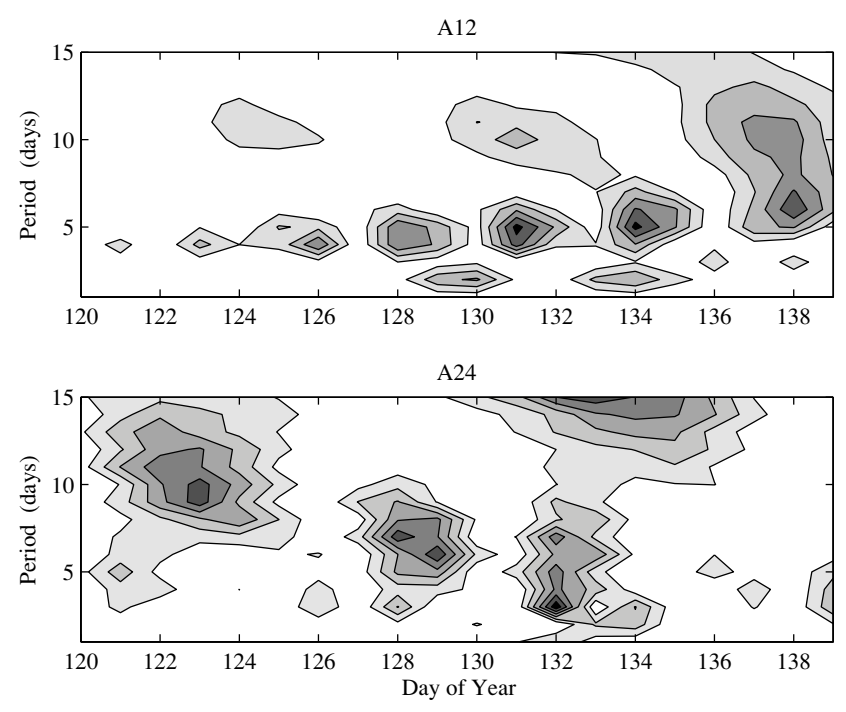

Fig. 9. Wavelet spectrograms for the amplitudes of the 12-h (top) and 24-h (bottom) periodicities in $f_{\mathrm{o}} E_{\mathrm{s}}$ during the period from day 120 to 140 of 2003 at Wuhan.

6-day modulations are clearly present at both periodicities. As it is known, the semidiurnal and diurnal periodicities are imprinted on $E_{\mathrm{s}}$ layers because the layer occurrence and strength are controlled mostly by the semidiurnal and diurnal tidal waves in the altitude range from 90 to $160 \mathrm{~km}$ (see Mathews, 1998; and a recent study by Haldoupis et al., 2006). The present result provides strong reassuring evidence in favor of an indirect PW role on $E_{\mathrm{s}}$ formation through the modulation of atmospheric tides, which is in full agreement with the findings of Pancheva et al. (2003).

\section{Summary and Concluding Comments}

We report here the first evidence in the Wuhan ionosonde and MLT neutral wind observations on the existence of a relationship between planetary wave oscillations and variations in sporadic $E$ layer occurrence. Here the characteristics of the long-term periodicities in $E_{\mathrm{s}}$ occurrence were studied to identify the prevailing periods and the duration of the dominant periodicities. Further, for the first time a direct comparison was attempted between the periodicities in $E_{\mathrm{s}}$ occurrence and simultaneous neutral winds, both measured at the same location (Wuhan). The wavelet spectrograms of both data sequences showed a very good agreement of the periodicities present concurrently in $E_{\mathrm{s}}$ occurrence and the MLT winds. Comparison of the 5- to 7-day band-pass filtered outputs of $E_{\mathrm{s}}$ occurrence and the wind data also show a good analogy. By investigating the phase changes with time of the quasi 6-day PW for all altitudes from 84 to $100 \mathrm{~km}$, the quasi 6-day PW in the zonal wind was found to be in phase with $E_{\mathrm{s}}$ at about $115 \mathrm{~km}$, an altitude that is near the observed mean $E_{\mathrm{s}}$ height of $111 \mathrm{~km}$. We also found both the 12- and 24-h periodicities in the $f_{\mathrm{o}} E_{\mathrm{s}}$ time series to undergo a strong quasi- 6 day modulation. The present results reinforce the postulation that the reported PW effects on $E_{\mathrm{s}}$ are basically induced indirectly through tidal modulations.

Relying on our findings we can infer that the periodicities in $E_{\mathrm{s}}$ occurrence are likely due to large-scale planetary waves, which are known to exist in the midlatitude mesosphere and lower thermosphere (see Forbes, 1994). The present results provide more evidence that PW play an important role in the formation of mid-latitude sporadic $E$ layers and support the findings of Haldoupis and Pancheva (2002), Pancheva et al. (2003), and Haldoupis et al. (2004). Also, the present findings favor an indirect $\mathrm{PW}$ role on $E_{\mathrm{s}}$ through a nonlinear process of PW modulation of the tidal wind amplitudes. The details of this mechanism need further study, in the framework of the wind shear theory, in order to be better clarified and understood. In addition, it is necessary to consider new driving forces in relation with PWs and their climatology are necessary in order to explain the $E_{\mathrm{s}}$ variability characteristics, such as, for example, the $E_{\mathrm{s}}$ annual occurrence. The thorough investigation of the PW physics on sporadic $E$ layer formation and strength is an important task which hopefully will be undertaken in a future study.

Acknowledgments. This work was supported by the KIP Pilot Project (kzcx2-yw-123) of the Chinese Academy of Sciences, National Important Basic Research Project (2006CB806306) and National Natural Science Foundation of China (40636032).

\section{References}

Forbes, J. M., Tidal and planetary waves, in The Upper Mesosphere and Lower Thermosphere: A Review of Experiment and Theory, edited by R. M. Johnson and T. L. Killeen, 67 pp, AGU, Washington, D.C., 1994. Haldoupis, C. and D. Pancheva, Planetary waves and midlatitude sporadic $E$ layers: Strong experimental evidence for a close relationship, J. Geophys. Res., 107(A6), 1078, doi:10.1029/2001JA000212, 2002.

Haldoupis, C., D. Pancheva, and N. J. Mitchell, A study of tidal and planetary wave periodicities present in midlatitude sporadic $E$ layers, J. Geophys. Res., 109, A02302, doi:10.1029/2003JA010253, 2004.

Haldoupis, C., C. Meek, N. Christakis, D. Pancheva, and A. Bourdillon, Ionogram Height-Time-Intensity observations of descending sporadic $E$ layers, J. Atmos. Solar-Terr. Phys., 68, 539-557, 2006.

Hocking, W. K., B. Fuller, and B. Vandepeer, Real-time determination of meteor related parameters utilizing modern digital technology, J. Atmos. Solar-Terr. Phys., 63, 155-169, 2001.

Holdsworth, D. A., I. M. Reid, and M. A. Cervera, Buckland Park all-sky interferometric meteor radar, Radio Sci., 39, RS5009, doi:10. 1029/2003RS003014, 2004.

Mathews, J. D., sporadic E: Current views and recent progress, J. Atmos. Solar-Terr. Phys., 60, 413-535, 1998. 
Pancheva, D., C. Haldoupis, C. E. Meek, A. H. Manson, and N. J. Mitchell, Evidence of a role for modulated atmospheric tides in the dependence of sporadic E layers on planetary waves, J. Geophys. Res., 108(A5),1176, doi:10.1029/2002JA009788, 2003.

Shalimov, S. and C. Haldoupis, A model of mid-latitude E-region plasma convergence inside a planetary wave cyclonic vortex, Ann. Geophys., 20, 1193-1201, 2002.

Shalimov, S., C. Haldoupis, M. Voiculescu, and K. Schlegel, Midlatitude E region plasma accumulation driven by planetary wave horizontal wind shears, J. Geophys. Res., 104, 28207-28213, 1999.

Smith, E. K., Worldwide occurrence of sporadic E, NBS Circular 582, U.S. Govt. Printing Office, Washington, D.C., 1957.

Torrence, C. and G. Compo, A practical guide to wavelet analysis, Bull. Am. Meteorol. Soc., 79, 61-78, 1998.

Tsunoda, R. T., M. Yamamoto, K. Igarashi, K. Hocke, and S. Fukao, Quasiperiodic radar echoes from midlatitude sporadic $E$ and role of the 5-day planetary wave, Geophys. Res. Lett., 25, 951-954, 1998.

Voiculescu, M., C. Haldoupis, and K. Schlegel, Evidence for planetary wave effects on midlatitude backscatter and sporadic $E$ layer occur- rence, Geophys. Res. Lett., 26, 1105-1108, 1999.

Voiculescu, M., C. Haldoupis, D. Pancheva, M. Ignat, K. Schlegel, and S. Shalimov, More evidence for a planetary wave link with midlatitude E region coherent backscatter and sporadic E layers, Ann. Geophys., 18, 1182-1196, 2000.

Xiong, J. G., W. Wan, B. Ning, and L. Liu, First results of the tidal structure in the MLT revealed by Wuhan Meteor Radar $\left(30^{\circ} 40^{\prime} \mathrm{N}, 114^{\circ} 30^{\prime} \mathrm{E}\right), J$. Atmos.-Terr. Phys., 66, 675-682, 2004.

Xiong, J., W. Wan, B. Ning, L. Liu, and Y. Gao, Planetary wavetype oscillations in the ionosphere and their relationship to mesospheric/lower thermospheric and geomagnetic disturbances at Wuhan $\left(30.6^{\circ} \mathrm{N}, 114.5^{\circ} \mathrm{E}\right)$, J. Atmos.-Terr. Phys., 68, 498-508, 2006.

Whitehead, J. D., The formation of the sporadic-E layer in the temperate zones, J. Atmos.-Terr. Phys., 20, 49-58, 1961.

Whitehead, J. D., Recent work on mid-latitude and equatorial sporadic E, J. Atmos.-Terr. Phys., 51, 401-424, 1989.

X. Zuo (e-mail: zuoxiaomin@yahoo.com.cn) and W. Wan 